\title{
Cama de Frango e Suplemento à Base de Microbiota Ruminal em Dietas de Novilhas Leiteiras: Desempenho Produtivo e Avaliação Econômica ${ }^{1}$
}

\section{José Carlos Pereira², Paulo Roberto de Carvalho e Silva ${ }^{3}$, Paulo Roberto Cecon ${ }^{4}$, Moisés de Andrade Resende Filho ${ }^{5}$, Ronaldo Lopes Oliveira ${ }^{6}$}

\begin{abstract}
RESUMO - O trabalho foi conduzido para avaliar o desempenho de novilhas de rebanhos leiteiros recebendo dietas contendo camade-frango (CF) e suplemento à base de microbiota ruminal (SMR). Foram utilizadas 20 novilhas mestiças Holandês-zebu, com peso médio inicial de $276 \mathrm{~kg}$ e idade média de 13,8 meses. Os animais foram distribuídos aleatoriamente em arranjo fatorial 2x2, no qual foram estudados dois níveis de CF (15 e 30\% na matéria seca) e de SMR (0 e 10 g/animal/dia), em delineamento inteiramente casualizado, com cinco repetições. Foram avaliados o consumo, o ganho de peso e a conversão alimentar e calculados os custos com alimentação, sendo composto um fluxo de caixa simulado para recria dos animais em confinamento e a pasto. Os consumos de matéria seca, matéria orgânica, proteína bruta e fibra em detergente neutro não foram influenciados pelos níveis de CF ou de SMR. O ganho de peso médio diário foi maior para as novilhas recebendo dietas com $15 \%$ de CF e $10 \mathrm{~g}$ de SMR (1,13 kg), em relação ao tratamento com $15 \%$ de CF sem SMR (0,85 kg). Entretanto, não houve diferenças em relação aos animais alimentados com 30\% de CF com e sem SMR (1,09 e 0,97 kg). Não foram observadas diferenças para conversão alimentar da matéria seca e da fibra em detergente neutro, e houve interação entre os níveis de camade-frango e de suplemento para a conversão alimentar da proteína bruta. Melhor relação custo/benefício foi encontrada para o tratamento $30 \%$ de CF sem SMR, em relação ao nível de $15 \%$ sem SMR, porém não-significativa para os demais. O fluxo de caixa simulado mostrou que o sistema de recria de novilhas em confinamento foi economicamente mais vantajoso que o sistema em regime de pasto, para as condições do presente trabalho.
\end{abstract}

Palavras-chave: conversão alimentar, gado leiteiro, ganho de peso, novilhas

\section{Broiler-litter and Supplement Based on Ruminal Microbiota in Dairy Heifers Diets: Performance and Economic Evaluation}

\begin{abstract}
This research was carried out to evaluate the performance of dairy heifers fed with broiler-litter (BL) and ruminal microbiota supplement (RMS). Twenty heifers, crossbred Holstein x zebu, with average weight and age of $276 \mathrm{~kg}$ and 13,8 months, respectively, were used. The animals were randomly allotted to a $2 \times 2$ factorial scheme: two levels of BL ( 15 and $30 \%$ in the diet dry matter) and RMS ( 0 and $10 \mathrm{~g} / \mathrm{heifer/day),} \mathrm{in} \mathrm{a} \mathrm{completely} \mathrm{randomized} \mathrm{design,} \mathrm{with} \mathrm{five} \mathrm{replications.} \mathrm{The} \mathrm{feed} \mathrm{intake,} \mathrm{weight} \mathrm{gain,} \mathrm{feeding} \mathrm{efficiency}$ and costs were evaluated, and an cash flow for feedlot and grazing systems was simulated. The intake of dry matter, organic matter, crude protein and neutral detergent fiber were not different for BL and RMS. Daily weight gain was higher for heifers fed diet with $15 \%$ BL and $10 \mathrm{~g}$ of RMS $(1.13 \mathrm{~kg})$, in relation to $15 \% \mathrm{BL}$ without RMS $(0.85 \mathrm{~kg})$, but without differences for animals receiving only $30 \%$ BL or with SMR (1.09 and $0.97 \mathrm{~kg}$ ). There were not differences in dry matter and neutral detergent fiber conversions, but there was an interaction between BL and RMS levels and efficiency of crude protein utilization. Costs/benefits ratio was better for the 30\% BL level, without RMS. Simulated cash flow showed that the feedlot system was economically more advantageous than grazing system, for the condition of this work.
\end{abstract}

Key Words: dairy cattle, feed efficiency, heifers, weight gain

\section{Introdução}

A criação de novilhas de reposição constitui um dos pontos de estrangulamento da pecuária de leite no Brasil, principalmente devido à falta de cuidados para proporcionar uma alimentação adequada para esses animais, o que acarreta baixa taxa de crescimento e, dessa forma, atraso para iniciar a vida produtiva.

Aproveitando a capacidade do ruminante em poder utilizar resíduos e subprodutos de baixa qualidade, a procura desta alternativa é um dos aspectos importantes para alimentação desta categoria animal, no sentido de diminuir os custos de produção sem afetar o seu desenvolvimento.

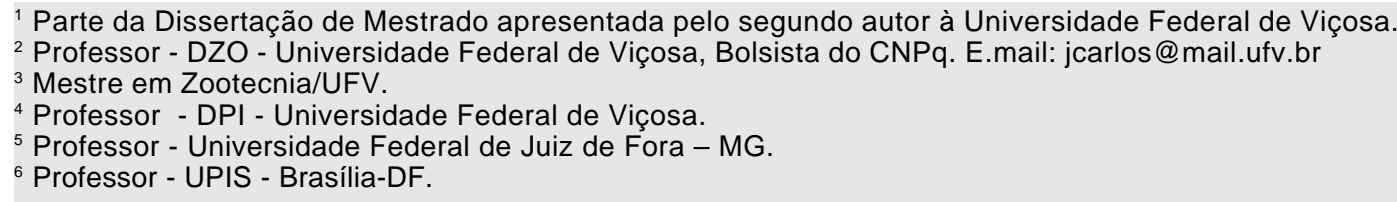


A cama-de-frango $(\mathrm{CF})$ tem sido fornecida para bovinos de diversas categorias, por ser um subproduto rico em proteína, e, dependendo da região, apresenta boa disponibilidade e custo adequado.

A utilização da CF na alimentação de bovinos é interessante, não apenas pelo seu valor nutritivo (Bathacharya \& Fontenot, 1966), como também pela sua disponibilidade e pelo baixo custo quando comparada a algumas fontes de proteína.

Porém, um ponto importante a ser considerado na utilização da $\mathrm{CF}$, é quanto ao aspecto sanitário, e neste sentido, Alexander et al. (1968) isolaram microrganismos como Salmonelas, Clostridium, Estafilococus e Enterobactérias do esterco de galinhas, mas não detectaram evidências de enfermidades transmissíveis aos ruminantes, exceto para bezerros e cordeiros, que podem ser contaminados com E.coli. A presença de Clostridium botulinumna CF também foi relatada por Dutra et al. (1992) e Polaquini et al. (1997).

Outro fato relacionado à $\mathrm{CF}$ é a presença de resíduos de antibióticos e coccidiostáticos, e que poderiam acumular nos tecidos dos animais alimentados com este subproduto. Também hormônios estrogênicos tem sido detectados, e Griel et al. (1969) relataram alta incidência de abortos em vacas recebendo CF na ração, e posteriormente tendo acesso a pastagem adubada com este subproduto.

A literatura relata vários trabalhos com os animais alimentados com $\mathrm{CF}$ fornecida em diversos níveis na dieta, e de modo geral, o desempenho é satisfatório, e variável em função de alguns fatores como nível de inclusão na dieta, composição da ração e material usado como substrato.

Outra tentativa de se obter maior eficiência na alimentação animal, consiste na utilização de probióticos. Com os recentes avanços na engenharia genética, essa tecnologia vem se desenvolvendo, principalmente no sentido de manipular a microbiota do animal hospedeiro, com influência positiva no seu desempenho e na sua saúde, sendo alternativa interessante no sentido de melhorar a nutrição e alimentação dos animais, já que como suplementos alimentares à base de microrganismos vivos, influem beneficamente no animal hospedeiro, promovendo o balanço da microbiota (Fuller, 1989).

Microrganismos vivos e outras espécies de células bacterianas têm sido usadas com o intuito de melhorar o desempenho do animal, por meio de melhor fermentação ruminal. Entretanto, os
Lactobacilus e outros microrganismos não sobrevivem no rúmen, embora uma população pequena possa ser mantida com a constante ingestão (Van Soest, 1994).

Hungate (1966) citou vários trabalhos utilizando microrganismos de bovinos adultos, inoculados em bezerros, e comenta que para conservar o inócuo, a liofilização é um processo bastante eficaz, apesar de ocorrem perdas de células microbianas durante o processamento.

Adams et al. (1981) encontraram ganhos de 1,39 e 1,34 kg/dia para animais recebendo suplemento à base de cultura de levedo e controle, respectivamente, e aumento na produção de leite foram observados por Huber et al. (1985), em animais recebendo suplemento à base de extrato da fermentação de Aspergillus orizae, e por Jaquete et al. (1988) e Ware et al. (1988), utilizando Lactobacillus acidophilus.

Sendo a atividade leiteira de baixa lucratividade, e considerando que os custos com alimentação constituem a principal parcela dos custos totais, a utilização de alimentos alternativos, de baixo custo, poderá propiciar maiores retornos financeiros, e neste sentido os objetivos deste trabalho foram avaliar o desempenho de novilhas leiteiras, além de efetuar uma avaliação econômica da produção, usando a CF associada a um suplemento à base de microbiota ruminal (SMR).

\section{Material e Métodos}

Foram utilizadas 20 novilhas com grau de sangue variando de 3/4Holandês-zebu a Holandês puro por cruza, idade média de 13,8 meses e peso vivo médio de $276 \mathrm{~kg}$, as quais foram alojadas em baias individuais apropriadas com $12 \mathrm{~m}^{2}$ de área, sendo $1 / 3$ coberta.

As rações experimentais foram calculadas com base nas exigências nutricionais do NRC (1989) para ganhos médios diários de $800 \mathrm{~g} / \mathrm{dia}$, e eram compostas por feno de capim coastcross (Cynodon dactylon $\mathrm{L}$.) moído grosseiramente, cama-de-frango $(\mathrm{CF})$ tendo como substrato o capim-elefante (Pennisetum purpureum, Schum.) picado e seco ao sol, e concentrado à base de fubá de milho, farelo de soja e mistura mineral. Além disso, em dois tratamentos foram adicionados $10 \mathrm{~g}$ de suplemento à base de microbiota ruminal (SMR), de acordo com a recomendação do fabricante (Vitatec ${ }^{\circledR}$ - FLENDS Indústria e Comércio Ltda.- Belo Horizonte-MG), o qual era misturado em pequena quantidade do concentrado previamente ao fornecimento da dieta total, para assegurar que os animais o consumissem. 
A CF utilizada ficou armazenada em galpão sob lona plástica, e não passou por processamento, por ser de procedência conhecida e não conter materiais estranhos.

No sentido de tornar as rações isoprotéicas e isoenergéticas, foram formulados dois concentrados diferentes compostos por fubá de milho, farelo de soja e mistura mineral, constituindo quatro tratamentos formados por dois níveis de CF (15 e 30\%) e dois níveis de SMR (0 e $10 \mathrm{~g} / \mathrm{animal} / \mathrm{dia})$, ou seja: Tratamento $\mathrm{CF} 15=15 \%$ de CF; Tratamento CF15/SMR = $15 \%$ de CF + 10 g/animal/dia de SMR; Tratamento $\mathrm{CF} 30=30 \%$ de CF e Tratamento CF30/SMR $=30 \%$ de $\mathrm{CF}+10 \mathrm{~g} / \mathrm{animal} / \mathrm{dia}$ de SMR.

A composição percentual dos ingredientes nas dietas encontra-se na Tabela 1 e a composição bromatológica dos ingredientes e das dietas totais, na Tabela 2.

Os animais passaram por um período de adaptação de 14 dias, onde recebiam as dietas experimentais, e ajustava-se o consumo, a fim de que na fase de coleta, as sobras fossem reguladas para uma quantidade de $10 \%$. O período experimental teve duração de 84 dias, e os animais recebiam a alimentação às 8 e $15 \mathrm{~h}$, e pela manhã as sobras do dia anterior eram retiradas e pesadas.

O consumo de alimentos foi obtido pela diferença entre a quantidade conhecida da dieta que era fornecida
Tabela 1 - Composição percentual dos ingredientes nas dietas experimentais (\% da matéria seca)

Table 1 - Percentual composition of the ingredients of the experimental diets (\% dry matter)

\begin{tabular}{lcc}
\hline $\begin{array}{l}\text { Ingredientes } \\
\text { Ingredients }\end{array}$ & $\begin{array}{c}\text { Dieta CF 15 } \\
\text { Diet BL } 15\end{array}$ & $\begin{array}{c}\text { Dieta CF 30 } \\
\text { Diet BL 30 }\end{array}$ \\
\hline $\begin{array}{l}\text { Feno de coastcross } \\
\text { Coastcross hay }\end{array}$ & 39,91 & 23,24 \\
$\begin{array}{l}\text { Cama de frango } \\
\text { Broiler litter }\end{array}$ & 15,00 & 30,00 \\
$\begin{array}{l}\text { Concentrado } \\
\text { Concentrate }\end{array}$ & & \\
$\begin{array}{l}\text { Fubá de milho } \\
\text { Corn, ground }\end{array}$ & 36,00 & \\
$\begin{array}{l}\text { Farelo de soja } \\
\text { Soybean meal }\end{array}$ & 8,60 & 3,50 \\
$\begin{array}{l}\text { Sal mineral } \\
\text { Mineral salt }\end{array}$ & 0,51 & 0,53 \\
\hline
\end{tabular}

e a sobra, e durante sete dias, ao longo de cada período de 28 dias, foram coletadas amostras das sobras que estavam no cocho pela manhã. As amostras das dietas fornecidas e dos ingredientes também eram coletadas neste mesmo período, sendo compostas por animal e por período. Nestas amostras foram determinados os teores de matéria seca (MS), matéria orgânica (MO) e proteína bruta (PB) conforme Silva (1990), e de fibra em detergente neutro e ácido (FDN e FDA), conforme Van Soest et al. (1991).

Tabela 2 - Teores de matéria seca (MS), energia metabolizável (EM), matéria orgânica (MO), proteína bruta (PB), fibra em detergente neutro (FDN) e fibra em detergente ácido (FDA) dos ingredientes e das dietas experimentais (\% da matéria seca)

Table 2 - Dry matter(DM), metabolizable energy (ME), organic matter(OM), crude protein (CP), neutral detergent fiber (NDF) and acid detergent fiber (ADF) contents of the ingredients (\% dry matter) and experimental diets

\begin{tabular}{|c|c|c|c|c|c|c|}
\hline $\begin{array}{l}\text { Ingredientes } \\
\text { Ingredients }\end{array}$ & $\begin{array}{l}\text { MS }(\%) \\
D M(\%)\end{array}$ & $\begin{array}{c}\mathrm{EM}(\mathrm{kcal} / \mathrm{kg})^{1} \\
M E(k c a l / k g)\end{array}$ & $\begin{array}{l}\text { MO } \\
\text { OM }\end{array}$ & $\begin{array}{l}\text { PB } \\
C P\end{array}$ & $\begin{array}{l}\text { FDN } \\
N D F\end{array}$ & $\begin{array}{l}\text { FDA } \\
A D F\end{array}$ \\
\hline $\begin{array}{l}\text { Feno coastcross } \\
\text { Coastcross hay }\end{array}$ & 88,31 & 1,47 & 94,75 & 5,54 & 84,19 & 46,81 \\
\hline $\begin{array}{l}\text { Cama-de-frango } \\
\text { Broiler litter }\end{array}$ & 74,78 & 1,85 & 81,12 & 18,14 & 66,90 & 39,26 \\
\hline $\begin{array}{l}\text { Fubá de milho } \\
\text { Corn, ground }\end{array}$ & 87,20 & 3,12 & 98,98 & 8,25 & 13,31 & 4,36 \\
\hline $\begin{array}{l}\text { Farelo de soja } \\
\text { Soybean meal }\end{array}$ & 87,62 & 3,26 & 99,00 & 52,20 & 12,68 & 10,57 \\
\hline $\begin{array}{l}\text { Concentrado CF15 } \\
\text { Concentrate BL15 }\end{array}$ & 87,61 & 3,15 & 97,17 & 16,64 & 11,44 & 6,93 \\
\hline $\begin{array}{l}\text { Concentrado CF } 30 \\
\text { Concentrate BL30 }\end{array}$ & 87,50 & 3,13 & 97,89 & 11,82 & 10,99 & 5,04 \\
\hline $\begin{array}{l}\text { Dieta total CF15\% } \\
\text { Total diet BL } 15 \%\end{array}$ & 85,97 & 2,30 & 93,81 & 12,43 & 48,76 & 27,68 \\
\hline $\begin{array}{l}\text { Dieta total CF 30\% } 83,87 \\
\text { Total diet BL 30\% }\end{array}$ & 2,36 & 92,13 & 12,26 & 44,76 & 25,01 & \\
\hline
\end{tabular}

EM (ME), kcal $/ \mathrm{kg}^{1}$ - NRC (1989). 
A pesagem dos animais foi realizada a cada 28 dias, sempre pela manhã, após decorridas 16 horas da última alimentação.

Para determinar os custos, considerou-se que os tratamentos foram aplicados em sistemas de produção que demandavam os mesmos insumos (instalações, mão-de-obra, terra, máquinas, equipamentos, entre outros), diferindo apenas quanto às dietas fornecidas, utilizando-se então, para quantificar o diferencial de custos entre um tratamento e outro, somente o cômputo das despesas com alimentação das novilhas confinadas. Com base na quantidade de alimentos consumida pelos animais e com os preços de mercado à época de realização do experimento (setembro/1996 a janeiro/1997), foi obtido o custo total com alimentação, durante o período de confinamento, por animal e tratamento.

Outro fator analisado foi o custo de alimentação até os animais atingirem $340 \mathrm{~kg}$ de peso vivo, e para isso foram utilizados os dados de ganho de peso diário dos animais em cada tratamento. Tendo como base o peso inicial das novilhas foram estimados os dias necessários para que atingissem $340 \mathrm{~kg}$ de peso vivo, em cada tratamento. Uma vez encontradas as relações médias de custo/benefício por tratamento, selecionou-se o que apresentou o menor valor do indicador mencionado, para ser usado em uma simulação do fluxo de caixa. Assim, procedeu-se à avaliação do impacto da realização da recria em sistema de confinamento, em comparação com a recria a pasto. Para realizar esta avaliação utilizou-se o método da análise do fluxo de caixa, o qual permite a consideração explícita do tempo na análise do investimento (Noronha, 1987). Com o objetivo de retratar um sistema de produção de leite semi-intensivo, típico de boa parte dos sistemas encontrados, foi realizada uma simulação de fluxos de caixa, construídos com base em índices zootécnicos, preços de insumos e produtos, animais, mão-de-obra, instalações, taxa de juros do mercado e estimativa do futuro potencial de produção dos animais, dados estes obtidos em diversas referencias (EMBRAPA, 1991; Gomes, 1996; FNP, 1996; AGRIDATA, 1997; FAESP, 1997; Resende Filho, 1997). Os índices de produtividade usados são apresentados na Tabela 3.

Foram elaborados dois fluxos de caixa com horizonte de planejamento de cinco anos, considerandose um rebanho de 20 fêmeas, partindo-se do ponto em que os animais apresentassem $270 \mathrm{~kg}$ de peso vivo (peso próximo à média dos animais no experimento).
Tabela 3 - Índices para simulação do fluxo de caixa para recria de novilhas leiteiras em confinamento e a pasto

Table 3 - Simulation cash flow indexes for dairy heifers raised in drylot and pasture systems

\begin{tabular}{lc}
\hline Item & Valor \\
Item & Value \\
\hline Número de novilhas no rebanho & 20
\end{tabular}

Number of heifers in the herd

Taxa de juros reais do mercado - $\%$ ao ano 6,0

Actual market interest rate - \% a year

Aluguel de pasto - R\$/animal/mês

Pasture rental - R\$/animal.month ${ }^{-1}$

Suplementos - R \$/animal/mês

Supplement - R\$/animal/month

Dose de sêmen - R\$

Dose of sêmen - $R \$$

Doses de sêmen/novilha

Semen dose/heifer

Mão-de-obra no confinamento - homem/animais

Labor cost in the feedlot-men/animals

Mão-de-obra pós-confinamento - homem/animais 1/50

Labor cost in the post feedlot - men/animals

Mão-de-obra a pasto - homem/animais

Labor cost in the pasture grazing system - men/animals

Preço estimado do bezerro ao nascer - $\mathrm{R} \$$

Estimated price for the male calf at birth $-R \$$

Preço estimado da bezerra ao nascer - R\$

Estimated price for the female calf at birth $-R \$$

Produção leite estimada/animal/lactação-lit.

Estimated milk yield/animal./lactation ${ }^{-1}$ - liters

Período de lactação - dias

Lactation period - days

Custo diário - $30 \mathrm{~kg}$ silagem milho/vaca lactante

Daily cost of $30 \mathrm{~kg}$ corn silage/milking cow - $R \$$

Custo diário-3 $\mathrm{kg}$ de concentrado/vaca lactante $\quad 0,54$

Daily cost of $3 \mathrm{~kg}$ concentrate/milking cow - R\$

Custo diário $30 \mathrm{~kg}$ capim-elefante/vaca seca

Daily cost of $30 \mathrm{~kg}$ elephantgrass/dry cow - $R \$$

Custo diário de $2 \mathrm{~kg}$ de concentrado/vaca seca - $\mathrm{R} \$ 0,36$

Daily cost of $2 \mathrm{~kg}$ of concentrate/dry cow - $R \$$

Preço de venda do leite - R \$/litro

Milk retail price- $R \$$ /liter

Custo da novilha aos $270 \mathrm{~kg}$

400,00

Heifer cost at $270 \mathrm{~kg}-R \$$

Valor de venda de vacas descartadas - R $\$ /$ vaca

Retail price of culled cows $-R \$ /$ cow

Custo da silagem de milho - R\$/tonelada 20,00

Corn silage cost $-R \$ / t$

Custo do capim-elefante - R\$/tonelada

Elephantgrass cost $-R \$ / t$

Ganho de peso animal/dia a pasto $(\mathrm{kg})$

Daily gain on pasture /animal day ( $\mathrm{kg}$ )

Ganho de peso/animal/dia em confinamento $(\mathrm{kg})$

Daily gain on feedlot/animal ( $\mathrm{kg}$ )

Custo das instalações/animal confinado - $\mathrm{R} \$$

Facilities cost/feedlot confined animal - $R \$$

Vida útil das instalações - anos

Housing lifespan - years

Salários e encargos/pessoa/mês

Monthly wages and duties

$\mathrm{US} \$=0,96$ 
Foram estabelecidos cinco anos como horizonte de planejamento de modo a avaliar o projeto durante a vida produtiva das vacas, constituída no presente caso, por quatro lactações, sendo as fêmeas em seguida descartadas e considerando o seu valor de mercado para corte.

Na primeira situação, considerou-se que as novilhas seriam alimentadas em sistema de confinamento, dos 270 aos $340 \mathrm{~kg}$, conforme o tratamento CF30, o qual apresentou a melhor relação custo/benefício. Ao atingirem 340 de peso vivo, considerou-se que as fêmeas seriam inseminadas e criadas a pasto até a parição, quando admitindo-se uma relação de sexo de $50 \%$, realizar-se-ia a venda dos bezerros e bezerras recém-nascidos. Daí em diante, as vacas permanecem produzindo leite por 10 meses, sendo que por ocasião do terceiro mês após o parto seriam fertilizadas, resultando desta maneira, em nova parição a cada doze meses. Desta forma permanecem secas por dois meses, entrando novamente em produção.

Na segunda situação simulada via fluxo de caixa, considerou-se que as novilhas seriam recriadas em regime de pasto dos 270 até aos $340 \mathrm{~kg}$, quando seriam inseminadas, e deste ponto em diante o fluxo segue as mesmas considerações adotadas na simulação do fluxo de caixa para as novilhas recriadas em confinamento.

As receitas advindas da venda do leite, bezerros, animais descartados e valor residual das instalações foram computadas na parte de "entradas" do fluxo de caixa. Foi estimado o custo da mão-de-obra usada para o manejo dos animais e o custo das instalações para o confinamento com base nos dados de Resende Filho(1997). O custo de alimentação dos animais em regime de pasto foi calculado utilizando como base o custo do aluguel de pasto, por ser a estimativa mais próxima ao cálculo devido à dificuldade de quantificar este valor na prática. Desta forma, pode-se comparar efetivamente essas duas situações avaliando economicamente os resultados de se confinarem os animais ou recriá-los a pasto, utilizando receitas e despesas geradas pelas duas situações. Para a avaliação dos resultados do fluxo de caixa, foram usados dois indicadores: o valor presente líquido e a taxa interna de retorno (Noronha, 1987; Azevedo Filho, 1988; Contador ,1988; Sang, 1988; Buarque,1991).

O valor presente líquido (VPL) foi calculado usando a fórmula:

em que $\mathrm{F}$ corresponde ao fluxo de caixa líquido relativo a cada período, com t variando de 0 até 4 , e r, à taxa de desconto relevante para a empresa em questão.

No presente estudo, utilizou-se a taxa de $6 \%$ ao ano, correspondendo à taxa de juros real da poupança.

A Taxa Interna de Retorno (TIR) é o valor de $r$ que permite igualar a zero o Valor Presente Líquido, sendo expressa da seguinte forma:

Com os resultados da Taxa Interna de Retorno e do Valor Presente Líquido, foi possível comparar os fluxos de caixa líquidos para as duas situações descritas, podendo-se inferir sobre qual delas seria a melhor alternativa de investimento.

$\mathrm{O}$ experimento foi conduzido seguindo delineamento inteiramente casualizado (DIC), em esquema fatorial $2 \times 2$, com cinco repetições, sendo dois níveis de CF (15 e 30\%) e dois níveis de SMR (0 e 10 g/ animal/dia), sendo os dados interpretados por análise de variância, adotando-se o nível de 5\% de probabilidade para o teste $\mathrm{F}$.

\section{Resultados e Discussão}

Os resultados dos consumos médios diários de MS, MO, PB, FDN são apresentados na Tabela 4, na qual se observa que não houve influência $(\mathrm{P}>0,05)$ dos níveis de CF ou de SMR na ração, indicando que os fatores atuaram de forma independente.

O consumo de MS de 8,91 e 9,57 e de PB de 1,07 e $1,10 \mathrm{~kg} /$ animal/dia, para os níveis de 15 e $30 \%$ de $\mathrm{CF}$, foram superiores àqueles preconizados pelo NRC (2001), para esta categoria animal, para ganhos de $1,0 \mathrm{~kg} / \mathrm{dia}$, o que certamente contribuiu para que os animais conseguissem atingir ganho de peso diário maior do que o citado anteriormente pelo NRC.

Estes resultados são diferentes dos apresentados por Arieli et al. (1991) e Brosh et al. (1993), que verificaram aumento no consumo de MS, quando se elevou a participação de CF na dieta oferecida aos animais.

Os resultados encontrados para consumo de MS, em \% do PV e g/kg PV ${ }^{0,75}$, foram próximos aos observados por Nogueira Filho et al.(1983), que trabalhando com novilhos em confinamento, com peso vivo médio de $255 \mathrm{~kg}$, alimentados com silagem de sorgo à vontade e concentrado composto por farelo de algodão, milho desintegrado com palha e sabugo e CF, obtiveram consumo de 2,70 e $3,14 \%$ PV, e 112,2 e $128,3 \mathrm{~g} / \mathrm{kg} \mathrm{PV}^{0,75}$, para níveis de 15 e $30 \%$ de CF. Resultados semelhantes foram encontrados por Oliveira et al. (1999), que também não observaram diferenças no consumo para 15 e $30 \%$ de $\mathrm{CF}$, associada ou não ao SMR. Entretanto, quando se observam osdados 
Tabela 4 - Consumos médios diários de matéria seca, matéria orgânica, proteína bruta e fibra em detergente neutro, em novilhas leiteiras recebendo dietas com diferentes níveis de cama de frango e suplemento de microbiota ruminal

Table 4 - Average daily dry matter, organic matter, crude protein and neutral detergent fiber intake by dairy heifers fed diets with different levels of broiler litter and ruminal microbiota supplement

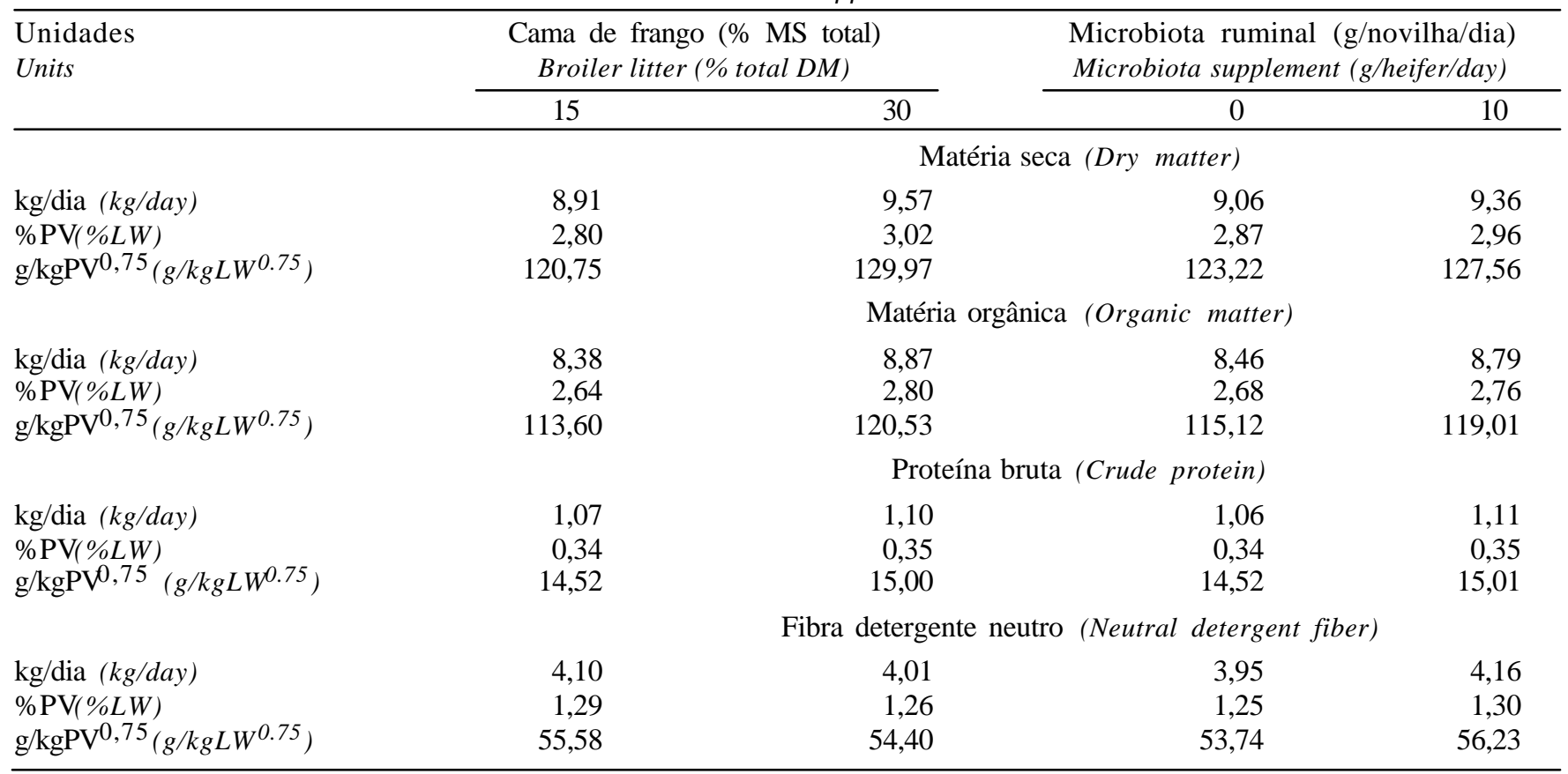

relativos a consumo de MS e PB, em valores absolutos, nota-se ligeiro incremento quando adiciona o SMR.

Diversos trabalhos tem mostrado efeitos benéficos da administração de probióticos, porém, a maioria tem sido realizados com bezerros em aleitamento, e poucos resultados existem para outras categorias animais, como novilhas em crescimento(Abe et al., 1995; Kay \& Poole, 1988).

Algumas teorias foram propostas para explicar o modo de ação dos probióticos, englobando mecanismos que parecem ser bastante complexos e incluem a produção de substâncias microbianas, competição por receptores de adesão, competição por nutrientes e imuno-estimulação, mas parecem ter estreita relação com fatores ambientais, microrganismo específico usado e condições de manejo e saúde do animal hospedeiro (Montes \& Pugh, 1993).

Mesmo no nível de 30\% de CF não houve diferenças $(\mathrm{P}<0,05)$ entre as dietas com 0 e 10 de SMR. Possivelmente a dose usada do suplemento não tenha sido suficiente para inocular microflora capaz de promover algum efeito, ou o tipo de microbiota presente no suplemento pode não ter sido o mais apropriado para a associar com dietas contendo nitrogênio não protéico e teores relativamente altos de fibra.

Os resultados relativos ao ganho de peso mostraram que houve interação $(\mathrm{P}<0,05)$ entre os níveis de CF e SMR (Tabela 5). Os animais que receberam a dieta contendo $15 \%$ de CF, associado ao SMR em nível de $10 \mathrm{~g} / \mathrm{animal} / \mathrm{dia}$, apresentaram maior ganho de peso $(\mathrm{P}<0,05)$ do que aqueles alimentados com o mesmo nível de CF, e sem SMR. Os ganhos foram de 0,85 e $1,13 \mathrm{~kg} /$ animal/dia, respectivamente, para os níveis de 0 e $10 \mathrm{~g}$ de SMR, dentro do nível de $15 \%$ de CF. Tal fato ocorreu provavelmente devido ao maior consumo de nutrientes apresentado pelos animais recebendo dieta com nível de $10 \mathrm{~g}$ de SMR. Para o nível de 30 de CF não foram encontradas diferenças $(\mathrm{P}<0,05)$ entre os ganhos de peso para as dietas com SMR.

Mutfic et al.(1969) obtiveram ganhos de peso de $1,2 \mathrm{~kg} /$ dia para novilhos confinados, alimentados com dietas contendo $40 \%$ de CF; e os ganhos de peso diário foram superiores aos encontrados por Cross \& Jenny (1976), com novilhas leiteiras para os mesmos níveis de CF deste trabalho.

Para a conversão alimentar da MS e da FDN não foram constatadas diferenças $(\mathrm{P}<0,05)$ entre os tratamentos, com valores de 10,$71 ; 8,68 ; 9,29 ; 9,90$ e 
4,$86 ; 4,04 ; 3,90$ e 4,41 , respectivamente para os tratamentos CF15, CF15/SMR, CF30 e CF30/SMR. Para a $\mathrm{PB}$ verificou-se interação $(\mathrm{P}<0,05)$ entre os fatores (Tabela 6). Neste caso, foram observadas diferenças entre as dietas com $15 \%$ de $\mathrm{CF}$, com melhor resposta para adição de SMR, conforme ocorreu com o ganho de peso. Com a administração do SMR, provavelmente conseguiu-se estabelecer uma população microbiana que pode ter melhorado a digestibilidade da dieta, aumentando a eficiência de utilização deste nutriente.

No presente trabalho utilizou-se o critério do custo de alimentação por $\mathrm{kg}$ de ganho de peso como uma «proxi» do custo médio por kg de ganho de peso. Presume-se assim, que a opção entre os tratamentos experimentais deve ser por aquele que resultar na melhor relação custo/benefício.

A quantidade gasta e preços dos alimentos, bem como os diversos custos, calculados para os quatro tratamentos podem ser vistos na Tabela 7 .

Os resultados do custo diário de alimentação mostram que para o nível de $15 \%$ de $\mathrm{CF}$, os animais recebendo dieta sem SMR apresentaram o menor valor ( $\mathrm{R} \$ 1,47 / \mathrm{dia})$, e o maior custo foi observado no tratamento com SMR (R\$1,71/dia).
De acordo com Jarquin Mejia (1995), há diferença entre eficiência técnica e econômica, onde a primeira depende do nível tecnológico empregado, e a segunda depende dos preços relativos e da produtividade obtida com a tecnologia empregada.

Assim, os resultados do custo/kg de peso ganho (Tabela 8), são bons indicadores da eficiência econômica de cada tratamento, uma vez que estão relacionados diretamente com o desempenho dos animais. Não houve efeito do SMR, e o tratamento CF30 foi o mais econômico, seguido por CF15/SMR e CF30/ SMR, sendo que CF15 apresentou a pior relação custo/benefício.

Quando aumentou o nível de CF, os custos de alimentação diminuíram, em função do menor preço deste ingrediente em relação aos demais, e o SMR não proporcionou aumento nos custos, pois os gastos com este produto foram muito baixos.

Os resultados do fluxo de caixa simulado para o sistema de recria em confinamento e a pasto, são mostrados na Tabela 9, onde analisando os valores obtidos para a TIR, a escolha recai sobre o sistema de recria em confinamento. O VPL foi maior para o sistema de confinamento. Este resultado corresponde à soma dos valores dos fluxos de caixa do sistema

Tabela 5 - Ganhos de peso médios (kg/animal/dia) de novilhas leiteiras recebendo dietas com cama de frango e suplemento de microbiota ruminal

Table 5 - Average live weight gains (kg/animal/day) of dairy heifers fed diets with broiler litter and ruminal microbial supplement Nível de cama de frango Suplemento microbiota ruminal

Broiler litter level

Ruminal microbiota suplement

\begin{tabular}{lcc}
\cline { 2 - 3 } & $0(\mathrm{~g} /$ animal/dia - g/animal/day $)$ & 10 (g/animal/dia - g/animal/day $)$ \\
\hline $15 \%$ & $0,85 \mathrm{aA}$ & $1,13 \mathrm{bA}$ \\
$30 \%$ & $1,09 \mathrm{aA}$ & $0,97 \mathrm{aA}$ \\
\hline
\end{tabular}

Médias seguidas pela mesma letra minúscula na linha e maiúscula na coluna não diferem pelo teste $F(P<0,05)$.

Means followed by a same small letter in the row and capital letter in the columm do not differ by $F$ test $(P<.05)$.

Tabela 6 - Conversão alimentar da proteína bruta por novilhas leiteiras recebendo dietas com cama-de-frango e suplemento de microbiota ruminal

Table 6 - Crude protein feed:gain ratio by dairy heifers fed diets with broiler-litter and ruminal microbiota supplement

Nível de cama de frango Suplemento microbiota ruminal

Broiler litter level Ruminal microbiota suplement

0 (g/animal/dia - g/animal/day) 10 (g/animal/dia - g/animal/day)

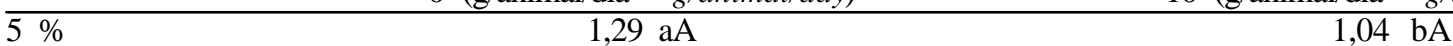

$30 \% \quad 1,07 \mathrm{aA} \quad 1,13 \mathrm{aB}$

Médias seguidas pela mesma letra minúscula na linha e maiúscula na coluna não diferem pelo teste $F(P<0,05)$.

Means followed by a same small letter in the row and capital letter in the columm do not differ by $F$ test $(P<.05)$.

R. Bras. Zootec., v.32, n.3, p.653-662, 2003 
Tabela 7 - Quantidade de alimentos gastos $(\mathrm{kg})$ e custos $(\mathrm{R} \$)$ com alimentação de novilhas leiteiras recebendo dietas com diferentes níveis de cama-de-frango e suplemento de microbiota ruminal

Table 7 - Total feeds expend $(\mathrm{kg})$ and feeding costs $(R \$)$ of dairy heifers fed diets with different levels of broilerlitter and ruminal microbiota supplement

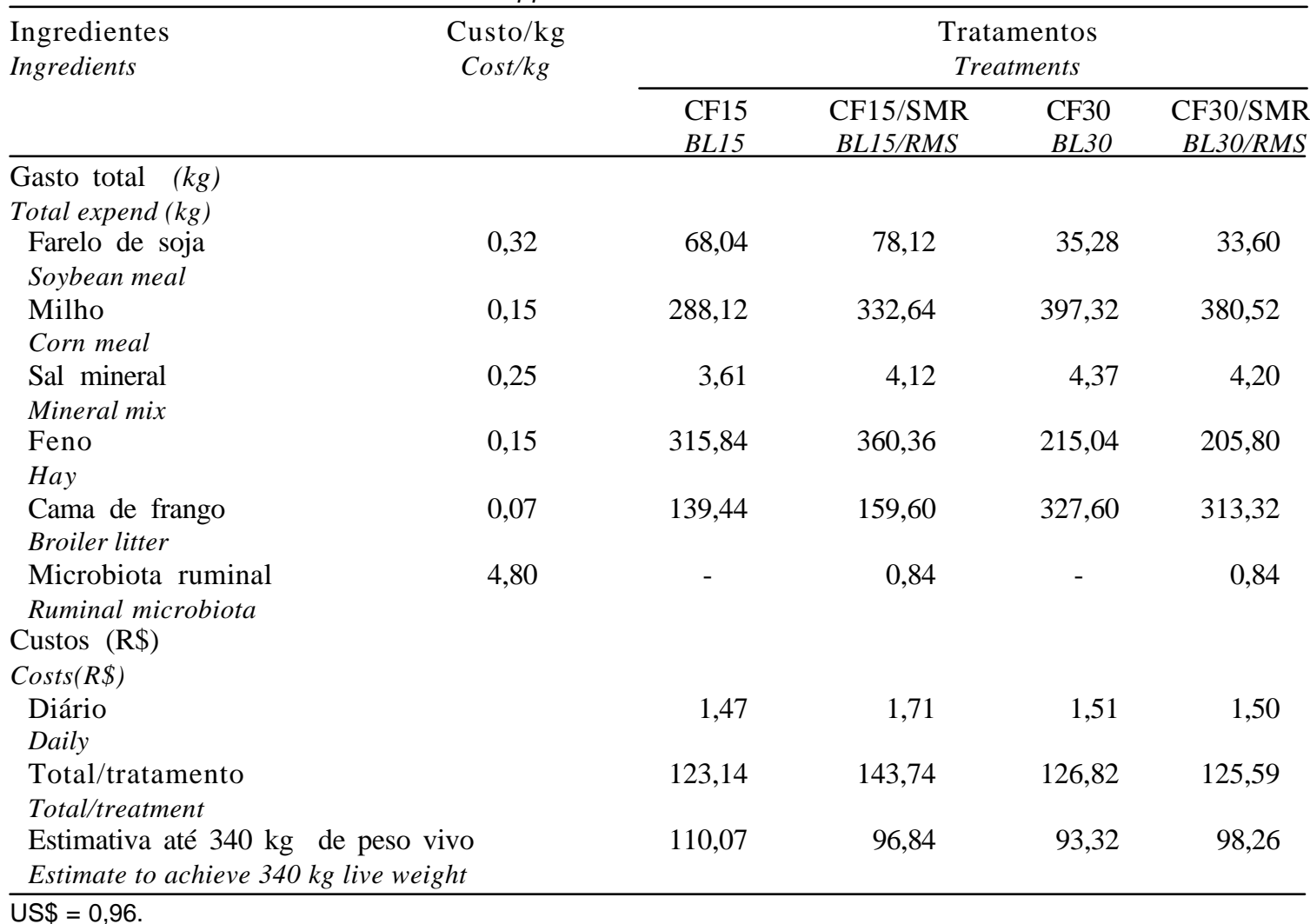

Tabela 8 - Relação custo da dieta e ganho de peso ( $R \$ / \mathrm{kg}$ ganho) em novilhas leiteiras recebendo dietas com cama de frango (CF) e suplemento de microbiota ruminal (SMR)

Table 8 - Diet cost and weight gain relation (Cost-R\$/weight gain-kg) by dairy heifers fed diets with broiler litter and ruminal microbiota supplement

\begin{tabular}{lcc}
\hline \multirow{2}{*}{$\begin{array}{l}\text { Nível de cama de frango } \\
\text { Broiler litter level }\end{array}$} & \multicolumn{3}{c}{$\begin{array}{c}\text { Suplemento microbiota ruminal } \\
\text { Ruminal microbiota suplement }\end{array}$} \\
\cline { 2 - 3 } & 0 (g/animal/dia - g/animal/day $)$ & $10(\mathrm{~g} / \mathrm{animal} / \mathrm{dia}-\mathrm{g} /$ animal/day $)$ \\
\hline $15 \%$ & $1,72 \mathrm{aA}$ & $1,51 \mathrm{aA}$ \\
$30 \%$ & $1,39 \mathrm{aB}$ & $1,55 \mathrm{aA}$ \\
\hline
\end{tabular}

Médias seguidas pela mesma letra minúscula na linha e maiúscula na coluna não diferem pelo teste $F(P<0,05)$.

Means followed by a same small letter in the row and capital letter in the columm do not differ by $F$ test $(P<.05)$.

Tabela 9 - Valor presente líquido (VPL) e taxa interna de retorno (TIR) do fluxo de caixa mensal simulado para recria de novilhas leiteiras de 270 a $340 \mathrm{~kg}$ de peso vivo em diferentes sistemas de confinamento e a pasto.

Table 9 - Net present value (NPV) and internal rate of return (IRR) of the monthly simulated cash flow for raising dairy heifers from 270 to $340 \mathrm{~kg}$ live weight in feedlot and pasture systems

\begin{tabular}{lcc}
\hline $\begin{array}{l}\text { Indice } \\
\text { Index }\end{array}$ & $\begin{array}{c}\text { Confinamento } \\
\text { Feedlot }\end{array}$ & $\begin{array}{c}\text { Pasto } \\
\text { Pasture }\end{array}$ \\
\hline $\begin{array}{l}\text { Valor presente líquido }(\mathrm{R} \$) \\
\text { Net present value }\end{array}$ & $20.418,07$ & $16.722,64$ \\
$\begin{array}{l}\text { Taxa interna de retorno }(\%) \\
\text { Internal rate of return }\end{array}$ & 3,26 & 2,87 \\
US\$ $=0,96$. & &
\end{tabular}


atualizados à taxa de desconto. A causa mais importante destes resultados é a obtenção diferenciada das receitas entre os sistemas. No confinamento os animais ganharam mais peso, completando o seu desenvolvimento mais rápido, e portanto, entrando em produção mais precocemente. A renda gerada por essa antecipação de receita é de fundamental importância para saldar os maiores investimentos inerentes ao próprio sistema. Pela lógica da TIR e do VPL, quanto maior o período de obtenção das receitas, mais deficitária é a atividade, pois os fatores são empregados na implementação do processo produtivo e devem ser remunerados a contento (Noronha, 1987).

\section{Conclusões}

A alteração do nível de cama-de-frango nas dietas, de 15 para $30 \%$, não causou prejuízos ao consumo alimentar ou ao ganho de peso das novilhas, e o suplemento de microbiota ruminal apresentou efeitos positivos apenas quando associado ao nível de $15 \%$ de cama-de-frango.

$\mathrm{O}$ aumento da cama-de-frango na dieta proporcionou diminuição nos custos da alimentação e, ao efetuar a simulação do fluxo de caixa, o sistema de recria das novilhas em confinamento mostrou-se financeiramente mais vantajoso que o sistema de recria a pasto.

\section{Literatura Citada}

ABE, F.; ISHIBASHI, H.; SHIMAMURA, S. Effect of administration of bifidobacteria and lactic acid bacteria to newborn calves and piglets.Journal of Dairy Science, v.78, p.28382846, 1995.

ADAMS, D.C.; GALYEAN, M.I.; KIESLING, H.E. et al. Influence of viable yeast culture, sodium bicarbonate and monensin on liquid dilution rate, rumen fermentation and feedlot performance of growing lambs and digestibility in lambs, Journal of Animal Science, v.53, p.780-789, 1981.

AGRIDATA Preços agropecuários no Estado de Minas Gerais, www.agridata.mg.gov.br/emater/owa/hestrc, 1997.

ALEXANDER, D.C.; CARRIERE, J.A.J.; McKAY, K.A. Bacteriological studies of poultry litter fed to livestock. Canadian Veterinary Journal, v.9, p.127-131, 1968.

ARIELI, A.; PECHT, Y.; ZAMWELL, S. et al. Nutritional adaptation of heifers to diets containing poultry litter.Livestock Production Science, v.28, p.53-63, 1991.

AZEVEDO FILHO, A.J.B. Análise econômica de projetos: "Software" para situações determinísticas e de risco envolvendo simulação. Jaboticabal: Universidade Estadual Paulista, 1988. 127p. Dissertação (Mestrado em Economia Rural) - Universidade Estadual Paulista, 1988.

BATTACHARYA, A.N.; FONTENOT, J.P. Protein and energy value of peanut hull and wool shaving poultry litters. Jour- nal of Animal Science, v.25, p.367-371, 1996.

BROSH, A.; HOLZER, Z.; AHARONI, Y. et al. Intake, rumen volume, retention time and digestibility of diets based on poultry litter and wheat straw in beef cows before and after calving. Journal of Agricultural Science, v.121, p.103109, 1993.

BUARQUE, C. Avaliação econômica de projetos uma apresentação didática. 6.ed. Rio de Janeiro: Atlas, 1991. 266p.

CONTADOR, C.R. Avaliação social de projetos. 2.ed. São Paulo, Ed. Atlas, 1988. 316p.

CROSS, D.L.; JENNY, B.F. Turkey litter silage in ration for dairy heifers. Journal of Dairy Science, v.59, p.919-923, 1976.

DUTRA, I.S.; WEISS, H.E.; WEISS, H. et al. Epizootiology of botulism of cattle in Brazil. In: CONGRESSO PANAMERICANO DE CIÊNCIAS VETERINÁRIAS, 13., 1992, Santiago do Chile.Anais...Santiago do Chile, 1992.p.86.

EMPRESA BRASILEIRA DE PESQUISA AGROPECUÁRIA - EMBRAPA. Custo de produção de leite. Brasília, DF., Câmara Setorial do Leite, 1991. 79p.

FEDERAÇÃO DA AGRICULTURA DO ESTADO DE SÃO PAULO- FAESP, . Indicadores de eficiência técnica e econômica na produção de leite. São Paulo, 1997. 90p.

FNP- CONSULTORIA E COMÉRCIO. Anuário estatístico da produção animal-ANUALPEC 9. São Paulo: Ed. Argos, 1996. 312p.

FULLER, R. Probiotics in man and animals. A review.Journal of Applied Bacteriology, v.66, p.365-378, 1989.

GOMES, S.T. Sistemas de preços de leite In: GOMES, S.T. (Ed.) A economia do leite, Coronel Pacheco, EMBRAPACNPGL, 1966. p.89-91.

GRIEL, L.C.; KRADEL, D.C.; WICKERSHAM,E.W. Abortion in cattle associated with the feeding of poultry litter. Cornell Veterinary, v.59, p.226-230, 1969.

HUBER, J.T.; HIGGIBOTHAM, G.E.; WARE, D. Influence of feeding vitaferm, containing an enzyme-producing culture from Aspergillus orizae on performance of lactating cows. Journal of Dairy Science, v.68, p.30, 1985 (Suppl.1).

HUNGATE, R.E. The rumen and its microbes. London: Academic Press, 1966. 533p.

JAQUETTE, R.D.; DENNIS, R.J.; COALSON, J.A. Effect of feeding viable Lactobacilus acidophilus(BT1386) on performance of lactating dairy cows.Journal of Dairy Science, v.71, p.219, 1988 (Suppl. 1).

JARQUIN MEJIA, J.M. Análise da eficiência técnica e econômica da utilização do farelo de gérmen de milho no desaleitamento precoce de bezerros, Viçosa, MG: Universidade Federal de Viçosa, 1995. 108p. Dissertação (Mestrado em Zootecnia) - Universidade Federal de Viçosa, 1995.

KAY, R.M.; POOLE, P.Lactobacilus acidophilus as a probiotic in the rearing of purchased calves. Animal Production, v.46, p.525, 1988 (Suppl. 3).

MONTES, A.J.; PUGH, D.G. The use of probiotics in food-animal practice. Veterinary Medicine, v.88, p.282-288, 1993.

MUTFIC, R.; DIZNIC, M.; DUGARSKI, D.L. Broiler litter as a basis component of rations in the fattening and prefattening of young black pied cattle. Veterinary Sata Jevo, v.18, p.467-475, 1969.

NATIONAL RESEARCH COUNCIL - NRC. Nutrient requirements of dairy cattle. 6.ed., Washington, D.C.: 1989. $157 \mathrm{p}$.

NATIONAL RESEARCH COUNCIL - NRC. Nutrient requirements of dairy cattle. 7.ed., Washington, D.C.: 2001. 381p. 
NOGUEIRA FILHO, J.C.M.; VELOSO, L.; BOIN, C. et al. Cama-de-galinheiro em rações para bovinos em acabamento. Boletim de Indústria Animal, v.40, p.21-24, 1983.

NORONHA, J.F. Projetos agropecuários: administração financeira, orçamento e viabilidade econômica. 2.ed. São Paulo: Atlas, 1987. 269p.

OLIVEIRA, R.L.; PEREIRA, J.C.; SILVA, P.R.C. et al. Consumo, digestibilidade e balanço de nitrogênio em novilhos alimentados com cama de frango e suplemento à base de microbiota ruminal liofilizada. Revista Brasileira de Zootecnia, v.28, p.831-838, 1999.

POLAQUINI, L.E.M.; SCHOCKEN-ITURRINO, R.P.; SORBARA, J.O. et al. Estudo da toxina botulínica e esporos de Clostridium botulinum em amostras de camas-de-frango coletadas em aviários. In: REUNIÃO DA SOCIEDADE BRASILEIRA DE ZOOTECNIA, 34., 1997, Juiz de Fora. Anais... Juiz de Fora: Sociedade Brasileira de Zootecnia, 1997. p.449-450.

RESENDE FILHO, M.A. Desenvolvimento de um sistema de apoio ao processo de tomada de decisão em confinamento de bovinos de corte, Viçosa, MG: Universidade Federal de Viçosa, 1997. 116p. Dissertação (Mestrado em Zootecnia) - Universidade Federal de Viçosa, 1997.
SANG, H.K. Project evaluation: techniques and practices for developing countries. New York: University of New York, 1988. 231p.

SILVA, D.J. Análise de alimentos: métodos químicos e biológicos. 2.ed. Viçosa, MG: Universidade Federal de Viçosa, 1990. 166p.

Van SOEST, P.J.; ROBERTSON, J.B.; LEWIS, B.A. Methods for dietary fiber, neutral detergent fiber and non starch polysacharides in relation to animal nutrition. Journal of Animal Science, v.74, p.3583-3597, 1991.

Van SOEST, P.J. Nutritional ecology of the ruminant. 2.ed. Ithaca, Cornell University Press, 1994. 476p.

WARE, D.R.; READ, P.L.; MANFREDI, E.T. Lactation performance of two large dairy herds fedLactobacillus acidophilus strain BT 1386 in a swithback experiment.Journal of Dairy Science, v.71, p.219, 1988 (Supp.1).

Recebido em: 22/02/02

Aceito em: 12/09/02 